\title{
Using Concept Maps Strategy in Developing the English Reading Comprehension Skills and Attitudes of Preparatory Students
}

\author{
A Thesis \\ Submitted for the Master Degree in Education \\ (Curriculum and Methods of Teaching English as a Foreign Language) \\ By \\ Shaimaa Hazem Hany Ragab
}

\author{
Supervised By \\ Prof. Dr. Aida Abel Maksoud Zaher \\ Professor of Curriculum and Methods of Teaching English \\ Faculty of Girls - Ain Shams University
}

Dr. Amira El-Amir khater

Assistant Professor of Curriculum and Methods of Teaching English

Faculty of Girls - Ain Shams University 


\section{ABSTRACT \\ Using Concept Maps Strategy in Developing the English \\ Reading Comprehension Skills and Attitudes of \\ Preparatory Students}

By

\section{Shaimaa Hazem Hany Ragab}

The purpose of this study was to investigate the effectiveness of concept maps strategy in developing some reading comprehension skills of first year preparatory students and improving their attitudes towards reading English texts. In order to fulfill the purpose of the study, the researcher designed a reading skills checklist which was administered to a jury of specialists in the field of TEFL to identify the reading comprehension skills that are necessary for the subjects of the study. Based on the chosen reading comprehension skills by the jury, the researcher designed a concept mapping strategy aiming at improving those skills. A pre-posttest and an attitude scale were also designed, judged and administrated to evaluate students' performance in reading comprehension skills and investigate their attitudes towards reading English texts. Seventy students in two classes were assigned into two groups, an experimental group $(\mathrm{N}=35)$ and a control group $(\mathrm{N}=35)$. Both groups were pre- and post- tested on both the same reading comprehension skills test and the same attitude scale. The experimental group studied the reading comprehension passages of their text book (first semester) following concept mapping strategy, while the control group studied the reading texts following regular instructions with their assigned teacher. Results of the data analysis showed statistically significant differences between the mean scores of the control and experimental groups on both the student reading comprehension preposttest and the attitude scale in favor of the experimental group students' performance. This was ascribed to the effectiveness of the concept mapping strategy in developing the experimental group students' reading comprehension skills and improving their attitudes towards reading in English. 
العدد التاسع عشر لسنة 1 1 ب r

Key words: Concept maps, Reading comprehension 


\section{ملخص}

\section{استخدام استراتيجية خرائط المفاهيم في تنمية مهارات الفهم القرائي و اتجاهات تلاميذ المرطلة الاعدادية نحو القراعة باللغة الإنجليزية}

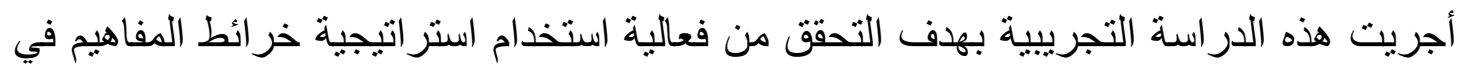

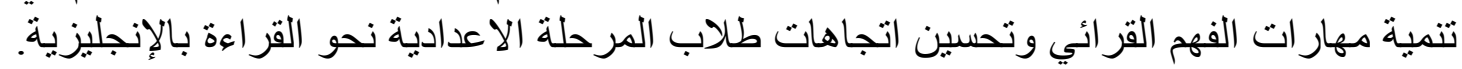
ومن أجل التحقق من الوصول للهدف الذى أجريت من أجله الدراسة، قامت التهات الباحثة بتصميم قائمة

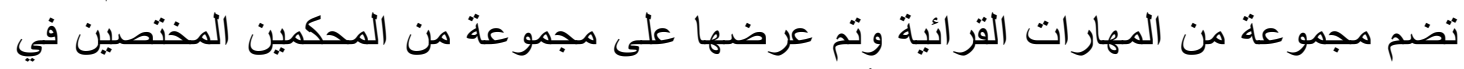

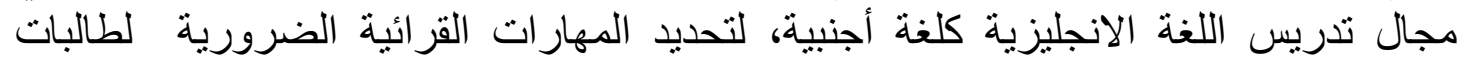

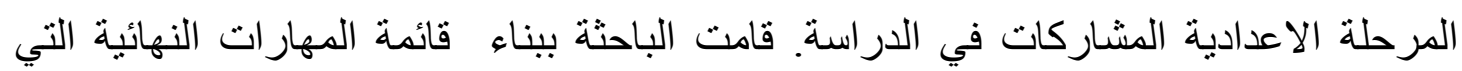
اختيرت بواسطة لجنة المحكمين و تصميم استر اتيجية مستندة على استخدام خرائط المات المفاهيم لتنمية تلك المهار ات. كما قامت الباحثة أيضا بتصميم اختبار قبلي-بعدى ومقياس اتجاه (استبيان)

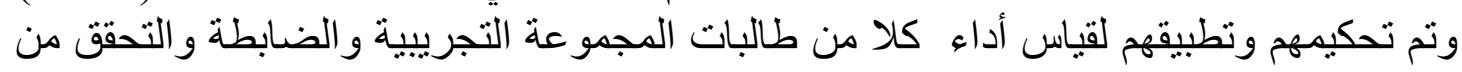

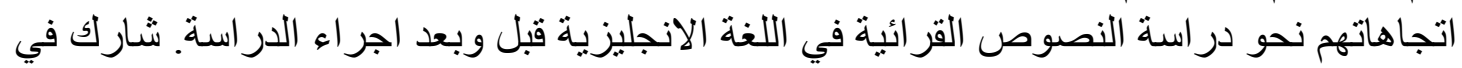

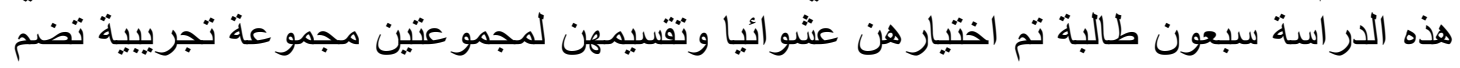
خمس وثلاثون طالبة وأخرى ضابطة تضم خمس وثثلاثون طالبة. أجرت طالبات كلتا

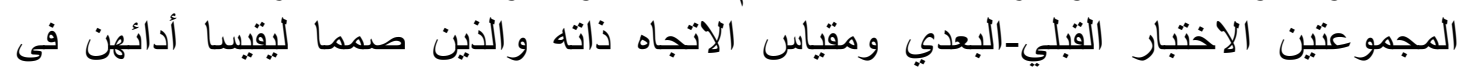

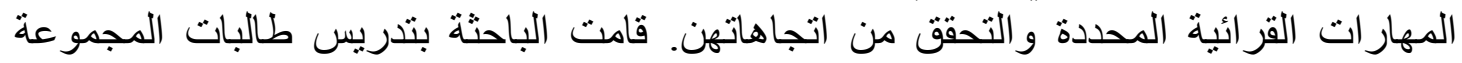

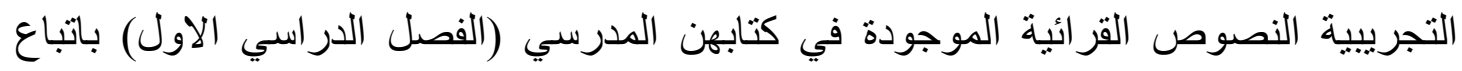

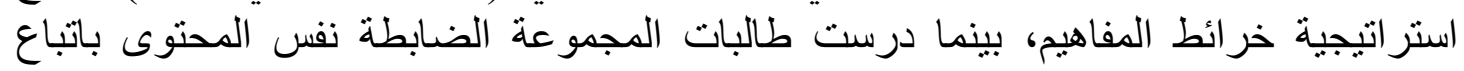

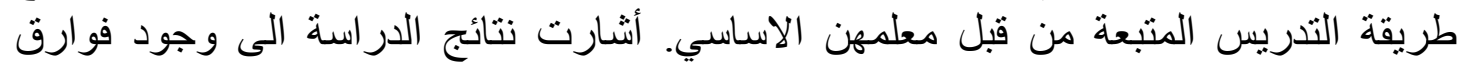

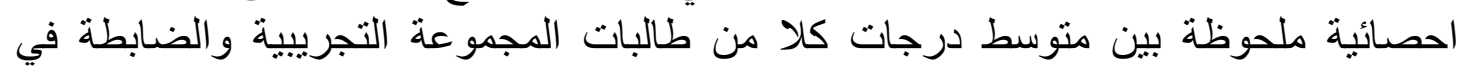

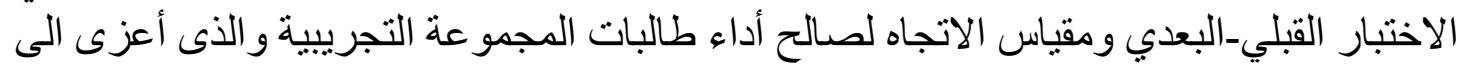

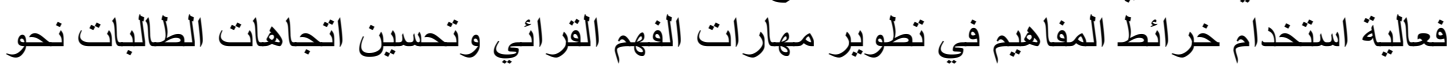
در اسة النصوص القرائية في اللغة الانجليزية. الكلمات الدالة: خرائط المفاهيم- الفهم القرائي.

\section{Introduction}

Reading comprehension is crucial to students' success in school, and further, to becoming lifelong learners. Children and young adults who struggle with reading comprehension will struggle with every subject in school, and with day to day living following school.

One way for helping students understand their reading is to find ways to connect the reading to a student's individual experiences. This is very 
difficult at a young age, due to the lack of life experiences and can be further hindered by limited exposure to a variety of people, places and things. Concept mapping is a spatial learning strategy that has been used for several decades in the sciences, as a way to show students the relationships between and among different scientific concepts. Ideally, it works with a student's prior experiences and knowledge to show relationships between current knowledge and new information, Cherie Dolehanty (2008).

David Novak developed the concept mapping technique in the 1970s at Cornell University. Novak and his research team based their work on David Ausubel's cognitive assimilation theories and the constructivist movement, both of which stress the importance of assimilating new information into previously learned structures.

A key notion in mapping information from a text is that of creating propositions that involve the linkage of two or more concepts with the use of "linking words or phrases to form a meaningful statement", Novak \& Cañas (2008). Various meaningful statements can be read from a concept map about any major concept that has been mapped. Another essential feature is that concept maps can become hypermedia documents when links are created to different types of media as, for example, to videos, animations, audio information. Concept maps can thus become a multimodal learning environment that will allow learners learn from the different representations provided by the specific features of each type of medium. For instance, learners can learn more about the history of cinema throughout time from a map that contains links to trailers of films, interviews with directors and staff, movie posters, thus adding hypermedia information to the graphic organization of the events hierarchically displayed on the digital screen, Reinildes Dias (2010).

Thus; this study attempts to use a concept mapping strategy for developing first year preparatory school students reading comprehension skills and improving their attitudes towards reading texts in English.

\section{Context of the problem}

In spite of the great importance of reading comprehension skills, they are neglected to some extent in learning and teaching English at the different stages of Education.

A preliminary study was conducted on a group of first year 
preparatory students in Meet El-Amel Preparatory School for Girls (AgaDakahlia-Egypt) to assess their reading comprehension skills. The study was composed of a comprehension test. The group consisted of (45) students. The reading comprehension test aimed at measuring the following skills: identifying the main ideas, extracting specific stated details, guessing the meaning of a word from context, determining pronoun referents, inferring specific details, recognizing cause-effect relationships, and recognizing a stated series of events in the correct sequence. The results were as follows:

* Seventy two percent $(72 \%)$ of the students showed weakness in identifying the main ideas of the text.

* About sixty percent $(60 \%)$ of the students showed weakness in extracting specific stated details.

* About ninety percent (90\%) of the students showed weakness in recognizing cause-effect relationships.

* Eighty five percent (85\%) of the students showed weakness in guessing the meaning of a word from context.

* Seventy five percent $(75 \%)$ of the students showed weakness in determining pronoun referent.

* Ninety two percent (92\%) of the students showed weakness in inferring a specific detail from the text.

* Sixty five percent (65\%) of the students showed weakness in recognizing a stated series of events.

\section{Statement of the problem}

The study problem can be identified in first year preparatory students' poor mastery of the required reading comprehension skills, in addition to the bad and negative attitudes towards reading in English and reading classes in general according to the researcher notes, which could be a result of traditional methods and techniques used by teachers in teaching reading at English classes.

So, the present study attempts to provide an answer to the following main question:

- What is the effectiveness of using concept mapping strategy in developing the reading comprehension skills of preparatory students and improving their attitudes towards reading in English?

From this main question, the following sub-questions emerge:

1 - What are the principles of concept mapping?

2- What are the features of the suggested strategy?

3- What are the reading comprehension skills necessary for preparatory stage students? 
4- How far is concept mapping strategy effective in developing the reading comprehension skills of first year preparatory students?

5- How far is concept mapping strategy effective in improving the students' attitudes towards reading in English?

\section{The study hypotheses}

1- There is a statistically significant difference between the mean scores of the experimental group students exposed to the proposed strategy and the control group students who received regular instruction on the reading comprehension posttest in favor of the experimental group students.

2- There is a statistically significant difference between the mean scores of the experimental group students exposed to the proposed strategy and the control group students who received regular instruction on each sub-skill of the reading comprehension posttest in favor of the experimental group students.

3- There is a statistically significant difference between the mean scores of the experimental group students on the reading comprehension pre-posttest in favor of the post-test.

4- There is a statistically significant difference between the mean scores of the experimental group students on each skill of the reading comprehension pre-posttest in favor of the post-test.

5- There is a statistically significant difference between the experimental group students exposed to the proposed strategy and the control group students who received the regular instruction in the post administration of the attitude questionnaire in favor of the experimental group.

6- There is a statistically significant difference between the mean scores of the experimental group students on the administration of the attitude pre-post questionnaire in favor of the postadministration.

\section{Variables of the study}

\section{* Independent variable:}

The strategy of concept mapping applied on the experimental group students versus regular instruction received by the control group students.

\section{* Dependent variables:}

1- The experimental group students' performance on the reading comprehension post-test.

2- The experimental group's attitudes towards reading in English on the post administration of the attitude questionnaire after experimentation of the strategy. 


\section{Delimitations of the study}

This study is delimited to:

1- Two groups of first year preparatory students randomly selected from a governmental preparatory school, one group as an experimental group and the second as a control one. Those students had been learning English for six years so they were supposed to possess the required linguistic skills that help in applying the strategy.

2- Using the topics of the prescribed textbook: Hello! English for first year preparatory students, first term.

3- Developing some reading comprehension skills in the literal and inferential levels because these levels are suitable for the study sample, which are as follows:

\section{Literal Skills}

1- Identifying the main ideas.

2- Understanding the chronological sequence and arranging the events of the text.

3- Identifying facts, key places, events and text details.

\section{Inferential skills}

1- Identifying cause and effect relationships.

2- Identifying pronoun referents.

3- Understanding text embedded ideas and information.

4- Visualizing ideas.

5- A period of a school term (approximately two months) for implementing the proposed strategy.

\section{Definition of Terms}

\section{Concept map:}

Concept map is a diagram showing the relationships among concepts. It is a graphical tool for organizing and representing knowledge. Concepts, usually represented as boxes or circles, are connected with labeled arrows in a downward-branching hierarchical structure. The relationship between concepts can be articulated in linking phrases such as "gives rise to", "result in", "is required by", or "contributes to" 
(Novac\& Canas, 2006).

In this study, it is defined operationally as a graphical diagram showing the relationships among concepts and organizing the information of English reading texts of first year preparatory stage. Those concepts and information are represented in boxes or circles and connected with labeled arrows in a downward-branching hierarchical structure in order to develop reading comprehension skills for first year preparatory students.

\section{Reading Comprehension:}

Sheng (2000) defines reading as the process of recognition, interpretation, and perception of written or printed material. Comprehension is the understanding of the written material and covers the conscious strategies that lead to understanding. The process of reading deals with language form, while comprehension, the end product, deals with language content.

In this study, it is defined operationally as the process of recognition, understanding and constructing meanings from English reading texts of first year preparatory stage, using concept mapping strategy.

\section{Theoretical Background}

Reading is a very complex skill, an interactive process, and a fundamental life-long learning tool. It involves many sub-skills such as vocabulary, grammar, phonetics, and comprehension.

Miyanaga (2007) states "Reading is the gate through which one recognizes the world of things and the lens by means of which one identifies what is going around him. Reading has occupied a very high status in the field of educational studies for centuries. Educators and linguists maintain that reading has a strong relation with every human activity. Reading gives them a chance to learn and enhance their knowledgment and enlarge their information".

Reading comprehension is considered the final and most essential objective of reading. People read for many reasons but understanding is always a part of their purpose. Reading comprehension is important because without it reading doesn't provide the reader with any information. 
Flindt (2007) identifies the process of reading comprehension as, " the complex cognitive process in which meaning is extracted through interactions between text and reader". Curtis and Kruidenier (2005) are in line with such a claim when they state "instructors should measure progress and asses learner's ability to acquire, use and infer information from text. Typically this can be done by asking students to read and answer questions about what they have read. Formats include multiple choice, short answer and cloze or fill-in-the-blank questions. Moreover, teachers can assess learner's knowledge of comprehension strategies such as asking questions while reading, writing summaries or creating outlines, by observing students while they read by asking them about the strategies they use".

Now this way (asking questions about the passage), is the traditional way to assess reading comprehension. Nowadays, researchers encourage teachers to use new strategies such as visual tools, graphic organizers and semantic webs which proved in various studies to be effective methods to assess their students' comprehension.

Information visualization is a well-studied, broad topic. Since the earliest cave paintings, man has consistently pursued more effective and elegant ways of conveying information. More recently, advances in technology and in our understanding of cognition and perception have led to new techniques and methods for visualizing information, Canas and others, (2006).

Concept maps are graphic or pictorial arrangements of the key concepts in a specific topic. They are usually presented in a hierarchical structure and showing the relationships between concepts. These maps are proved by several studied to be useful tools that can be utilized to represent the information and one's own knowledge of learning materials in a form that is psychologically compatible with the way human beings construct meaning, Canas (2006). When created correctly and thoroughly, concept mapping is a powerful way for students to reach high levels of cognitive performance. A concept map is also not just a learning tool, but an ideal evaluation tool for educators measuring the growth of and assessing students' learning. As students create concept maps, they reiterate ideas using their own words and help identify incorrect ideas and concepts; educators are able to see what students do not understand, providing an accurate, objective way to evaluate areas in which students do not yet grasp concepts fully. 


\section{Concept mapping serves several purposes for learners:}

- Helping students brainstorm and generate new ideas.

- Encouraging students to discover new concepts and the propositions that connect them.

- Allowing students to more clearly communicate ideas, thoughts and information.

- Helping students integrate new concepts with older concepts.

- Enabling students to gain enhanced knowledge of any topic and evaluate the information.

Concept mapping has been used for teaching/planning, learning and assessing learning, though most applications seem to be in the sciences, rather than related to reading comprehension. Since Novac's first work of concept mapping strategy on science and other fields of education, many educators attempted to examine the effectiveness of this strategy on reading comprehension.

Dolehanty (2008) conducted a study to observe and measure the effects of concept mapping on reading comprehension, in an English lab course at the secondary level. The method was to explicitly teach concept mapping as a reading strategy and collect data in the following ways: reading comprehension placement results (pre- and post-tests); student self-evaluations; and daily observational journals. Data was collected through the following instruments: (1) storage of the maps created by the students in a virtual space; (2) assessment of the quality of the maps by me (that is, how much the created maps reflected an understanding of what was read). The assessment criteria involved three words of appraisal: fair - good - very good; and (3) narratives that were written by them about their experience with developing a specific visual strategy to enhance reading comprehension in English. Present research corresponded to the researcher assessment of what students created based on the texts. The results of the study indicated the improvement of the experimental group.

The purpose of Dreye's (2012) mixed-methods study was to determine if when implemented at one two-year post-secondary institution, such K-12 reading comprehension strategies as concept mapping, think-aloud protocols, and Question-Answer Relationships (QAR) elicit change in COMPASS reading test scores of adult readers. 
Data was collected over four academic semesters at one two-year postsecondary institution. Pre- and post-test scores were compared using SPSS () software. Data indicated that while statistical significance did not occur, the numerical difference is noteworthy. The researched developmental reading intervention strategies did improve COMPASS post-test scores for a greater percentage of students in the experimental group than those students in the control group. From these two improvements the researcher was able to conclude that there searched developmental reading intervention strategies infused into the traditional developmental curriculum caused students to improve.

\section{Method and Procedures of the Study}

\section{Design of the study}

The design used in this study is the quasi pre-posttest experimental design. Two first year prep school classes were randomly selected to implement the strategy. The two classes represented the experimental and the control groups. The experimental group received instruction through a strategy consisting of three phases to improve their reading comprehension skills. Students of the control group received regular reading classes with their in charge teacher. The pre-posttest was conducted before and after the treatment. An attitude questionnaire was applied before and after the administration of the study to measure first year prep stage students' attitudes towards reading.

\section{Participants of the study}

The participants of this study were 70 students in first year preparatory, Meet El Amel prep school for girls, Aga, Dakahlia. The 70 students were representing two classes, control (35) and experimental (35). All students' age ranged from 12-13. The experimental group studied the reading comprehension passages of their text book (first semester) following the proposed strategy, while the control group studied the reading texts following the regular method. A pre-test was administrated for both groups before administrating the study. The results showed that $t$-values were not significant at 0.05 level of confidence and this showed that there was no significant difference between both groups on the pre-test in the seven reading comprehension skills. Thus, any gains the experimental group got on the post-test would be due to the treatment. 


\section{Tools of the study}

Three main tools were used in this study to investigate the research hypotheses and answer the research questions:

1- A reading comprehension checklist consisting of three literal and four inferential reading comprehension skills.

2- A pre-posttest to measure students' mastering of reading comprehension skills.

3- An attitude questionnaire to measure students' attitudes towards reading English texts before and after implementing the strategy.

\section{The Teaching Strategy}

\section{Rationale of the strategy}

The most important rationale of this strategy is the use of concept mapping to develop the reading comprehension skills and attitudes of first year preparatory stage students towards reading English texts.

Concept mapping was specifically proposed as a tool for improving reading comprehension by Novac. Concept mapping contributes to student confidence by letting students demonstrate what they know rather than forcing them to explain what they do not know as in traditional testing. The process helps encourage meaningful learning and creative thinking and replaces rote learning and memorization.

\section{Aim of the strategy}

This study aims at investigating the effectiveness of using a concept mapping strategy in developing the reading comprehension skills and attitudes of preparatory school students towards reading classes in English.

\section{Teaching Materials}

This strategy is represented in the following thirteen lessons in the students' textbook:

Lesson 1: Introductory workshop (introducing concept mapping).

Lesson 2: Unit 1 lesson 1: Proud to be Egyptian.

Lesson 3: Unit 1 lesson 4: All about me. 
Lesson 4: Unit 2 lesson 1: My family at work.

Lesson 5: Unit 3 lesson 1: Food.

Lesson 6: Unit 4 lesson 1: Welcome to Cairo.

Lesson 7: Unit 5 lesson 1: A dirty canal.

Lesson 8: Unit 6 lesson 1: Water for all.

Lesson 9: Unit 6 lesson 4: The Nile floods.

Lesson 10: Unit 7 lesson 1: Shops and shopping.

Lesson 11: Unit 8 lesson 1: City and country.

Lesson 12: Unit 9 lesson 1: Possessions.

Lesson 13: Unit 9 lesson 4: Egyptian music.

Objectives of the strategy

By the end of the strategy students will be able to show mastery of the following skills:

1- Identifying the main ideas.

2- Understanding the chronological sequence and arranging the events of the text.

3- Identifying facts, key places, events and details stated in the text.

4- Identifying cause and effect relationships.

5- Identifying pronoun referents.

6- Understanding text embedded ideas and information.

7- Visualizing ideas.

\section{Teacher's Guide}

The researcher prepared a teacher's guide to help English teachers in teaching these lessons using concept mapping strategy. The teacher's guide was prepared in the light of previous literature in the field of reading comprehension skills.

\section{Sections of the guide}

\section{Introduction to the guide}


The guide introduction aimed at introducing concept mapping strategy to English teachers beside the reading comprehension skills improved by the strategy. The introduction presented the behavioral general objectives for all the lessons taught by the proposed strategy.

\section{Behavioral objectives of each lesson}

The objectives of the teaching lessons were formulated according to the concept mapping strategy and the selected reading comprehension skills. These following objectives represented the expected learning outcomes that students should achieve by the end of implementing the concept mapping strategy:

1- Identifying the main ideas.

2- Understanding the chronological sequence and arranging the events of the text.

3- Identifying facts, key places, events and details stated in the text.

4- Identifying cause and effect relationships.

5- Identifying pronoun referents.

6- Understanding text embedded ideas and information.

7- Visualizing ideas.

\section{Teaching aids and materials:}

The researcher included -in the teachers' guide- a list of instructional aids and tools that can be used while teaching the strategy:

1- Students' work books.

2- Data show.

3- Teaching videos.

4- Pictures, charts, and graphic organizers.

5- Board.

6- Blank sheets.

\section{Time allocation for strategy lessons}

Teacher's guide contains a proposed time plan for each lesson of the teaching strategy. Each lesson consisted of three activities besides the 
evaluation. The researcher proposed an appromoxitly time for each activity.

\section{Teacher's Guide Validity}

The teacher's guide was judged by a panel of professors in the department of curriculum and instruction in Ain Shams University and by English language teachers and supervisors to make their opinions on the suitability of the behavioral objectives, teaching aids and educational activities for lessons included in the study. The Jury approved the teacher's guide and proved its validity for the goals of the study.

\section{Application of the strategy: method and activities}

The researcher followed three stages in teaching reading texts while applying this strategy. These stages are the pre-reading stage, during reading stage, and post- reading stage. Each one of those three stages includes activities and techniques which help students develop their reading comprehension skills, better remember information, encourage them control their own learning, and improving their attitudes towards reading English texts.

\section{1- pre- reading stage:}

This stage enables students to understand the reading text without looking up every single word. This stage also provides opportunities for class discussion activities:

1- The teacher activated and assessed students' background knowledge and schema in regards to the target text.

2- The teacher gave students the necessary background knowledge needed for comprehending the text.

3- The teacher made students aware of the type of text they will read and the purpose(s) of reading.

* Concept mapping was used as:

1- A pre-reading strategy by inviting students to share what they already know about a particular concept.

2- Students began reading and adding to the map, they were able to meld their prior knowledge with new information they gathered from their reading.

\section{2- During or while - reading stage:}


In this stage:

1- The teacher asked students to read the whole text silently.

2- They were asked to look at the text and extract specific information.

3- The teacher asked students to identify topic sentence that contained the main idea of the text ( the main concept), recognizing the details ( detailed concepts of the text) connected to the main idea or concept, and identifying the linking words that connect main concepts with detailed ones. The teacher guided students to use these extracted information to construct a concept map. Some activities of this stage are:

* Identifying topic sentences which contains the main idea and the most important concept of the paragraph.

*Identifying the key (places, characters, events .....etc).

* Distinguishing between general and specific ideas (concepts).

*Identifying pronoun referents.

*Identifying cause and effect relationships.

*Understanding text embedded ideas and information.

* Understanding the chronological sequence and arranging the events of the text.

\section{3- Post reading stage:}

In this stage, it was very important to make students share and discuss different ideas related to the reading text, as not all people got the same information by:

1- Summarizing what was read and revising their notes.

2- Learning how to visualize ideas.

3-Constructing a concept map(s) using the extracted concepts and information from the text.

4- Encouraging students to share their concept map(s) with one another in pairs or small groups. This allowed students to share and reflect on how they each interpreted the connections between concepts and words. 
5- Encouraging students to use their map(s) to summarize what they have read, organize their writing, or to create a study guide for their own studying and reviewing.

\section{Teaching Procedures}

1- The present research was undertaken based on the need to enhance first year prep school students' reading comprehension of texts written in English.

2- Throughout this challenging process, making students aware of conscious use of reading strategies can help them become successful readers is very vital.

3- Phelps mentioned when teachers present new strategies in small steps, model the strategy carefully, and provide opportunities for ongoing feedback as students practice the strategy with increasing independence, students achieve maximum benefit from this method.

4- More than that, anticipating the types of problems students may encounter when using the strategy or how to use the strategy helps teachers make the explicit strategy instruction beneficial and clear.

Thus; the researcher conducted few steps before applying the strategy:.

* The researcher explained to students the aim of the strategy and the skills they are going to learn, and how this method will enhance their reading comprehension skills through learning how to draw and construct concept maps for the texts they read.

* Letting students understand that, while creating a visual representation of what they read, they could relate the arguments and ideas discussed in the text more effectively, clearly and easily.

* The researcher handed a portfolio to each student for her own work (concept maps for the target texts).

* The researcher checked that every member of the experimental group had the text book.

* The researcher checked the resources and aids were used to carry out the strategy, the video maker, data show and charts. 
* The researcher adopted the scaffolding method in teaching students how to construct a concept map, first the researcher used a simple text related to their daily life (for example, personal information about one or two of the students) and present these information in a map.

* The researcher told students they made one (or two) concept map (s) for every reading text of their text book.

* The researcher told students that in the first 5 lessons they were only going to make maps similar to the ones they study, but after that they would be asked to construct maps of the texts by their own.

* The researcher used the observation cards to take notes of students' improvement in making concept maps.

* The researcher assessed students' attitude towards reading before and after using this strategy.

\section{Duration of the strategy}

The strategy was applied in two months (November \& December) during the first semester of the academic year 2015-2016. It consisted of thirteen lessons, two lessons weekly. The researcher applied the pre- test and the pre-questionnaire to both the (experimental and control groups) on Sunday first of November 2015 before the experimentation. At the end of the strategy, both posttest and post administration of the questionnaire have been administered on Sunday third of January 2016 .

\section{Study Results}

- The results showed that concept mapping strategy has a positive effect on reading comprehension skills of prep stage students. The students in the experimental group got better scores in the posttest compared to the control group students' scores. These findings are consistent with those of Jo's (2001), Romance and Vitale's (2001), Han's(2006), Chang, Sung \& Chen (2007), Dolehanty (2008), Chang and Yu (2010), James (2011), Kalhor\& Mehran (2017), in that applying the concept-mapping strategy had a direct effect in developing students' reading comprehension skills.

- The results also showed that the students who learned using the concept-mapping strategy revealed significantly superior performance in terms of each reading comprehension sub-skill in the posttest compared to their performance in the pre-test. 
- The results of the study showed the effectiveness of concept mapping strategy in improving the attitude of the experimental group students and that there is a statistically significant difference between the experimental group students exposed to the proposed strategy and the control group students who received the regular instruction in the post administration of the attitude questionnaire in favor of the experimental group. In addition, the experimental results also showed that, there is a statistically significant difference between the mean scores of the experimental group students on the administration of the attitude pre-post questionnaire in favor of the post-administration.

\section{Discussion of the results}

According to the results of this study, concept mapping has showed effectiveness in developing reading comprehension skills of the experimental group students and improving positively their attitudes towards reading classes and reading English texts. Thus, these results will be discussed in the following points:

1- Students in the experimental group were taught through using the suggested reading strategy based on concept mapping, these students achieved better results than their peers of the control group because these students were given the opportunity to practice the strategy with the researcher in the classroom.

2- The scaffolding method used by the researcher while teaching -the experimental group students- concept mapping strategy, helped them easily learn how to construct a concept map for any English text by their own.

3- The activities used during administrating the study and the threestages helped students to manage the proposed reading comprehension skills and improve them.

4- The steps of constructing a concept map automatically lead students to master different reading comprehension skills, students should identify the main concept of the text- identifying the main ideas-, then students start finding the detailed concepts related to the main ones - Identifying facts, key places, events and text details-. If the text is about a short story or a serious of events, then students should represent it in the correct order Understanding the chronological sequence and arranging the events of the text-. While constructing the map students have to 
represent the relations between concepts of the text through using the labeled arrows -Identifying cause and effect relationships, Identifying pronoun referents, Understanding text embedded ideas and information.

5- The student-centered classroom and the semantical drawings (visualization) which were provided through applying the concept mapping strategy, helped students to fully and actively participate in the class which lead them eventually to understand each reading text and improve their attitude towards reading classes.

Thus, concept mapping strategy is very effective at many levels, besides visualizing the ideas in a semantic web, it helps students fully understand and easily review the reading text through applying all these activities while constructing each map. Concept maps also helped the students to fully understand and master each one of the proposed reading comprehension sub-skills. In addition, concept mapping showed great effect in improving students' attitude towards reading English texts.

\section{Conclusions}

This study investigated the effectiveness of developing some reading comprehension skills and improving the attitudes of the first year preparatory students towards reading English texts through using concept mapping strategy. So, the following conclusions were drawn:

- Concept mapping strategy was found to be effective in developing the seven target reading comprehension skills (Identifying the main ideas, Understanding the chronological sequence and arranging the events of the text, Identifying facts, key places, events and text details. Identifying cause and effect relationships, Identifying pronoun referents, Understanding text embedded ideas and information, Visualizing ideas.

- The findings of the study revealed that the concept mapping strategy was influential in developing the reading comprehension skills and improving students' attitude towards reading texts in English.

- Based on the results, it is recommended that, the learners use concept map to deepen their learning and improve academic achievements therefore, Executives and educators in the field of 
education could use the concept map as a teaching strategy, learning task and assessment tool in education.

- The three stages -pre, during and post reading- the researcher followed during the strategy, helped students to fully understand the reading texts and correctly construct a concept map for each one.

- Student-centered classroom is one of the main aims of teaching concept mapping strategy. Students are urged to think for themselves, take decisions, evaluate which are the main concepts and the detailed ones of the text. Students are encouraged to take control of their leaning and make more effort to fully comprehend the target text.

- This strategy helps students learn how to learn. Concept mapping contributes to student confidence by letting students demonstrate what they know. Visual learning helps students clarify their thoughts. Students see how ideas are connected and realize how information can be grouped and organized. With visual learning, new concepts are more thoroughly and easily understood when they are linked to prior knowledge. Visual learning helps students organize and analyze information. Students can use diagrams and plots to display large amounts of information in ways that are easy to understand and help reveal relationships and patterns. Visual learning helps students integrate new knowledge. According to research, students better remember information when it is represented and learned both visually and verbally. Thus, visual leaning including concept mapping helps students learn better, easier and faster, so improving students' attitudes towards reading texts in English.

\section{Recommendations}

On the basis of the experimental study and its results, the following recommendations are provided:

- Teachers should consider applying concept mapping strategy in reading classes if they are aiming at stirring students attention and making their classes more interesting and unbarring, as this study showed the effectiveness of concept mapping strategy in improving 
positively the attitudes of the experimental group students towards reading English texts and they agreed that this study made them like reading classes more.

- Students should be provided with effective and long term training methodologies to fully understand the concept mapping strategy before using it in English texts.

- This study showed the effectiveness of concept mapping strategy in developing meaningful learning and creative thinking and replaces rote learning and memorization.

- Concept mapping is recommended as an effective strategy in enhancing self-learning and student-centered methods of teaching.

- It is recommended that teachers should change their teachercentered method of teaching. Students should take control of the process of their own learning. Teachers role should be only attributed to directing students through learning and checking their worksheets.

- Concept mapping is not an easy strategy to be covered in the allotted time. Thus, it is recommended to expand the time allotted for the English reading classes.

\section{Suggestions for further research}

Based on the results of this study, the researcher presents some suggestions for further research:

1- A proposed research based on concept mapping strategy to develop writing, reading and listening skills of all the educational levels.

2- Investigating the effectiveness of concept mapping strategy in developing critical reading skills for secondary stage.

3- Examining the effectiveness of concept mapping strategy of improving -all educational levels- students' attitude towards reading English texts.

4- Designing a strategy based on concept mapping to develop grammar and vocabulary improvement.

5- Investigating the effectiveness of concept mapping strategy on developing reading comprehension skills of short and long stories. 
6- Executives and educators in the field of education could investigate the effectiveness of concept mapping as a teaching strategy, learning task and assessment tool of all educational levels.

\section{Lesson 1}

\section{An introductory for the strategy}

Title: Introducing the concept of concept mapping

Learning objectives: Students will be able to:

1- Recognize the general aim of the training strategy.

2- Recognize the concept of concept mapping.

3- Recognize the different types of concept maps.

4- Make a simple characteristic concept map.

\section{Material needed:}

1- Computer graphics.

2- Watching video (movie maker).

3- Board

Time: 2 hours

\section{Procedures:}

The procedures of this lesson consisted of 3 activities.

Activity one:

Breaking the ice, the researcher asks students some questions and give them 5 minutes to think of the answer.

1- What is the meaning of strategy? 


\section{2- Have you ever heard about concept mapping or graphic organizers?}

* The teacher listens to students' answers and discusses them orally.

* The teacher explains to students that this strategy aims at developing their reading comprehension skills and improving their attitudes towards reading English texts, through using concept mapping.

* The researcher explains the meaning of reading skills and discuss with students each skill they are going to improve.

\section{Activity two:}

\section{Introducing concept mapping}

* The researcher starts to attract students' interest through telling them that they are going to learn something new which will improve their ability to understand English texts better and make reading class more fun and exciting.

* The researcher introduces concept mapping to students as an essential tool of visual learning.

Concept mapping is one type of Information visualization which is a well-studied, broad topic. Visual thinking is a learning style where the learner better understands and retains information when ideas, words and concepts are associated with images. Research tells us that the majority of students in a regular classroom need to see information in order to learn it. Some common visual learning strategies include creating graphic organizers are concept mapping, diagramming, mind mapping, outlining and more.

\section{Examples of graphic organizers}




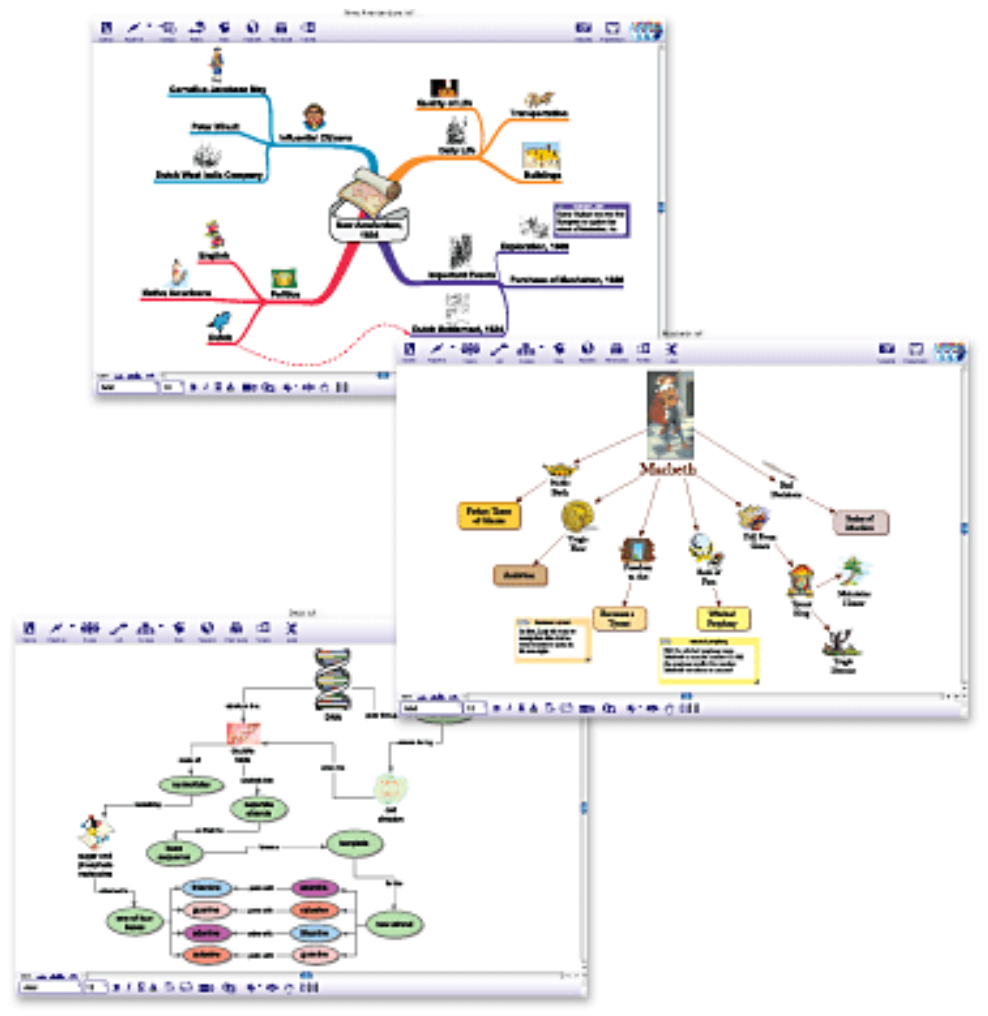

- $\quad$ The researcher explains the concept of concept mapping and its great importance in developing their learning and attitudes towards reading English texts, in simple words and enhances this explanation by drawing on board and showing students computer graphics and pictures of graphic organizers and concept maps.Concept mapping is one of the most important types of graphic organizers. Concept map as a graph consisting of nodes and labeled lines. The nodes correspond to important terms (representing concepts) in a domain. The connecting lines denote a directional relationship between a pair of concepts (nodes). The label on the line (explanation) conveys how the two concepts are related. The combination of two nodes and a labeled line is called a proposition. A proposition is the basic unit of meaning in a concept map and the smallest unit used to judge the validity of the relationship drawn between two concepts, like this one: 


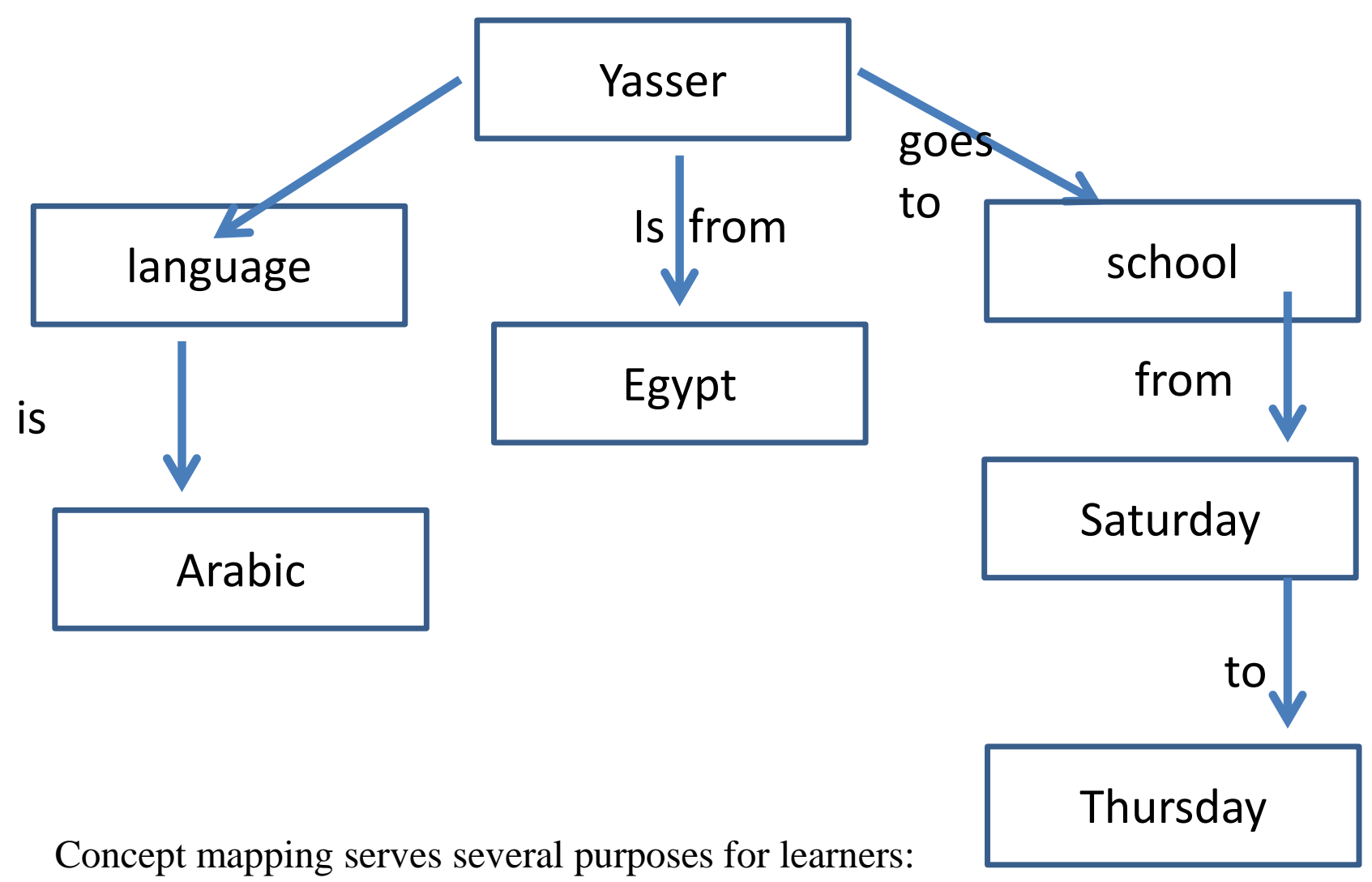

- Helping students brainstorm and generate new ideas.

- Encouraging students to discover new concepts and the propositions that connect them.

- Allowing students to more clearly communicate ideas, thoughts and information.

- Helping students integrate new concepts with older concepts.

- Enabling students to gain enhanced knowledge of any topic and evaluate the information.

- Contributing to student confidence by letting students demonstrate what they know rather than forcing them to explain what they don't know as in traditional testing.

* The researcher tells students that Concept maps can be constructed in different types and shapes according to the content of the topic they present. For example, a map of telling a sequence of events of a story will be different from a map that describing a character in the same story. Here are some types of concept maps: 


\section{a)Problem-Solution Map}

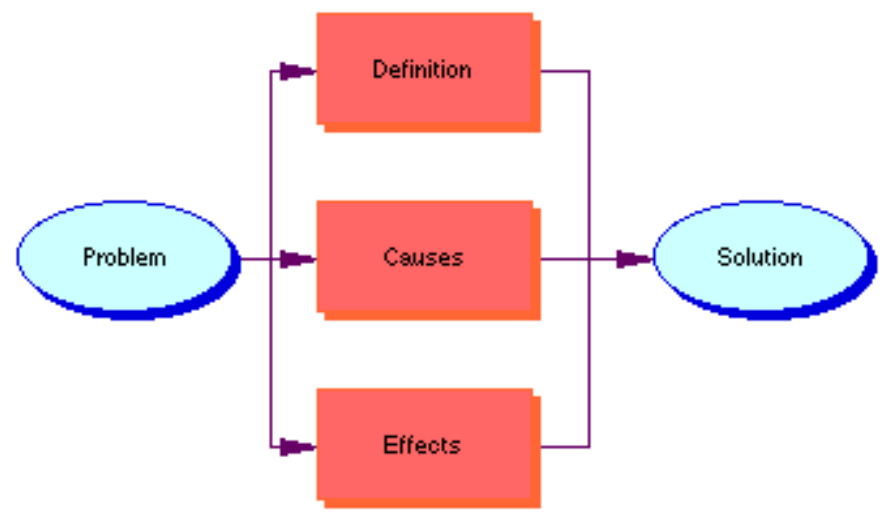

A fairly straightforward map is a problem-solution map. In this, students have a problem statement, definition, causes, and effects, leading to a possible solution.

\section{b) Process Development Map}

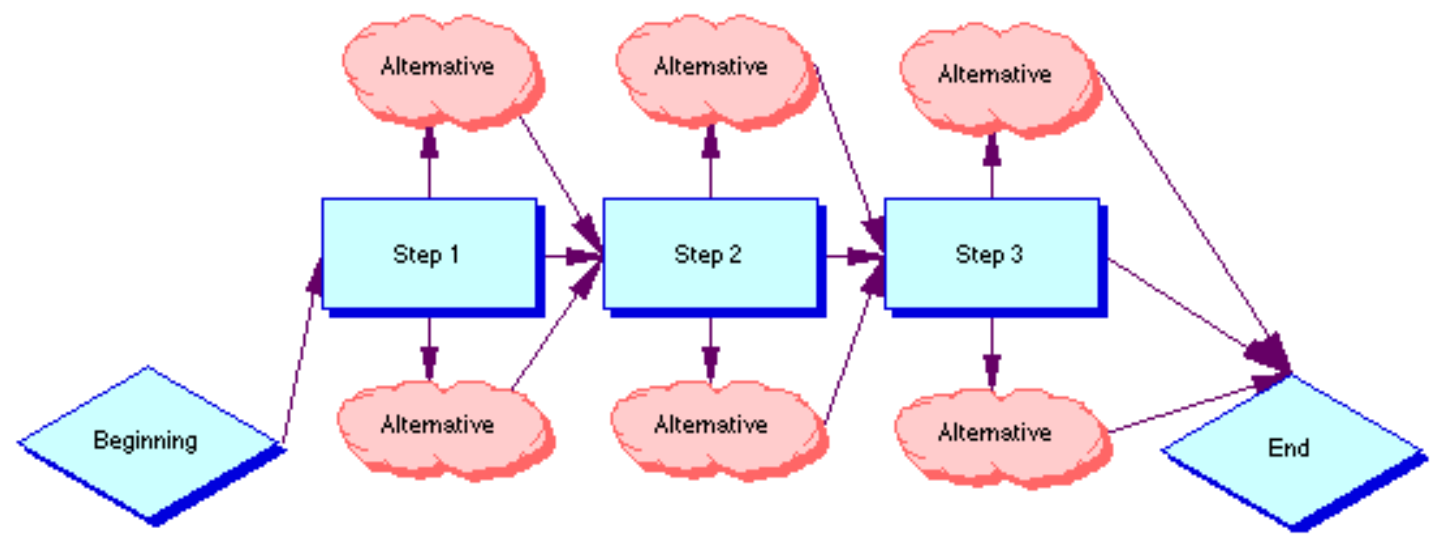

A more involved assignment asks students to create a process for accomplishing a task. There is a beginning and an end, with multiple steps and alternatives at each step.

\section{c) Persuasive Argument}




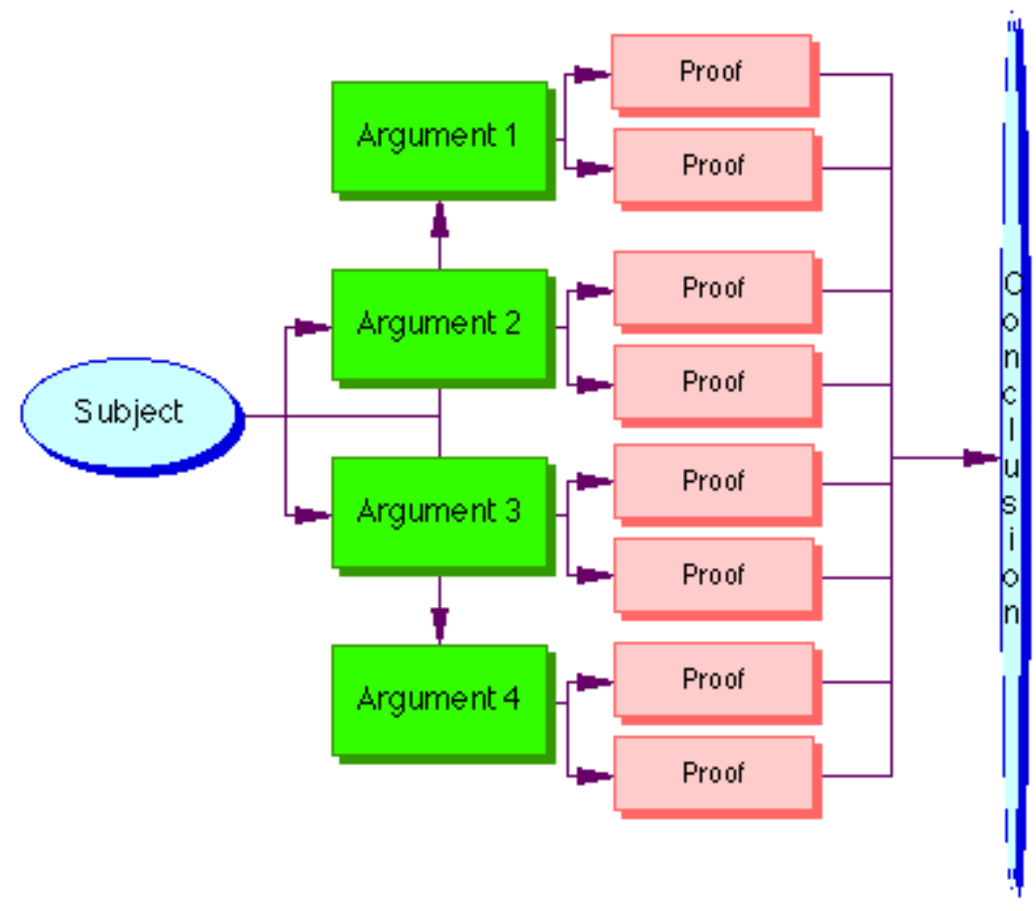

Here is a fairly common type of theme for students, in which they present a persuasive argument.

\section{d) Characteristics}

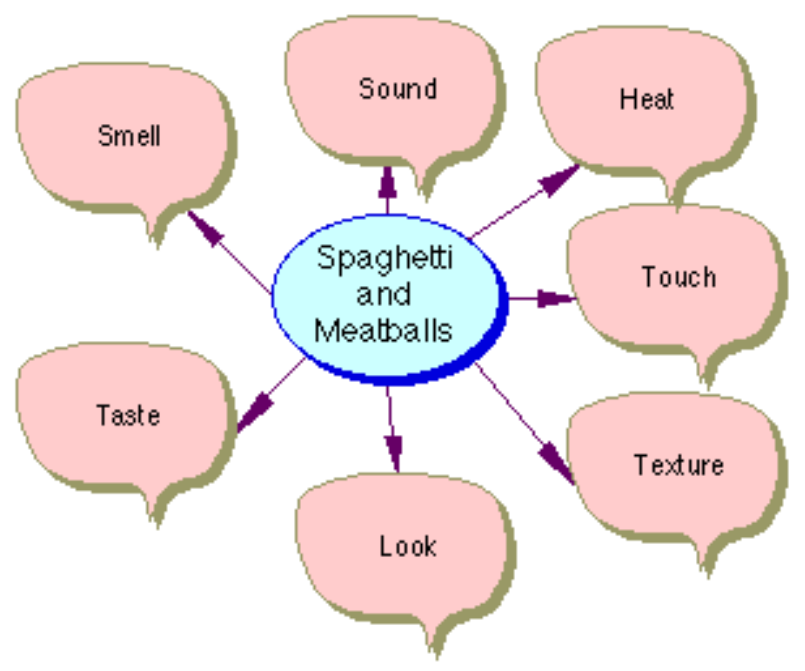

Here, a much more free-form map might ask students to think about the characteristics of something — say, spaghetti and meatballs.

\section{e) Research Topic}




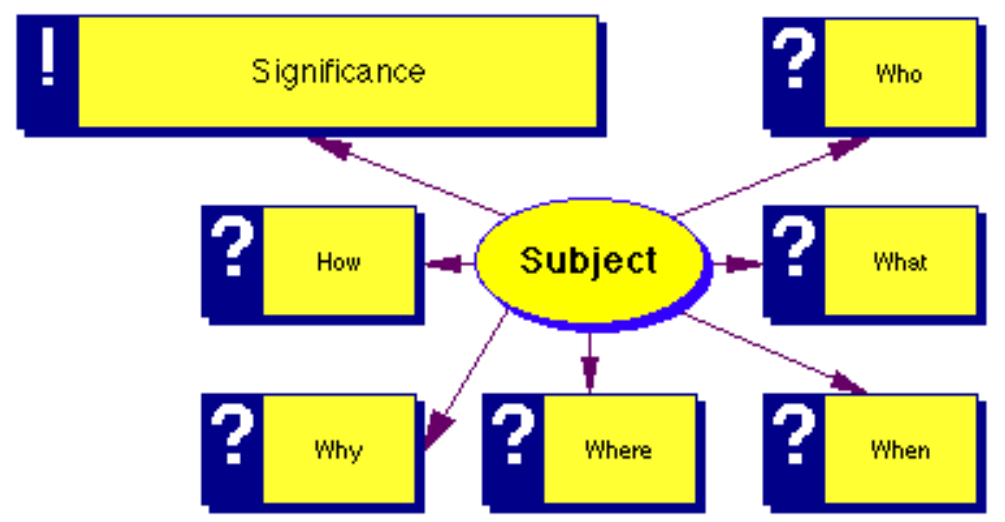

A more research-y take on description asks students to research a topic, adding to the map in who, what, when, where, why, how fashion leading toward the significance of a topic.

\section{f) Narrative Story Line}

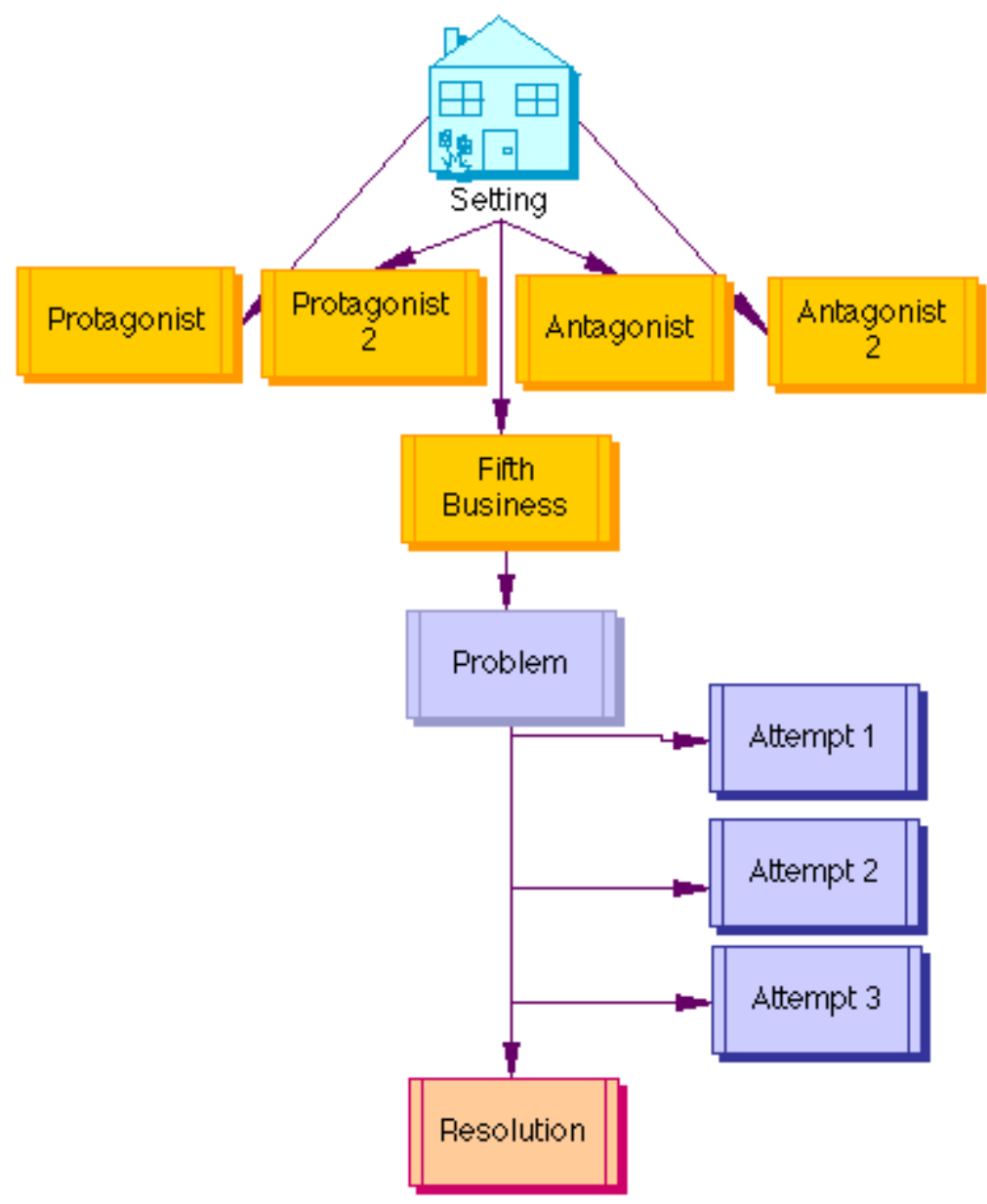

A narrative story line might look like this, with a setting, set of characters, problem, set of alternative attempts to solve the problem, and a resolution.

\section{Activity Three:}


- The researcher starts to teach students how to make a correct concept map.

- The researcher shows students a video presenting making a concept map.

- First, start with a good focus question, whether provided by the teacher or the learner. The more focused and robust the question, the better the resulting concept map.

Second, one should identify key concepts having to do with the topic question, list them, and rank them in order of importance.

Next, construct a preliminary map with the central concepts near the top and sub-topics arranged below, with crosslinks between them.

Finally, go back in and define the relationship that the crosslink represents.

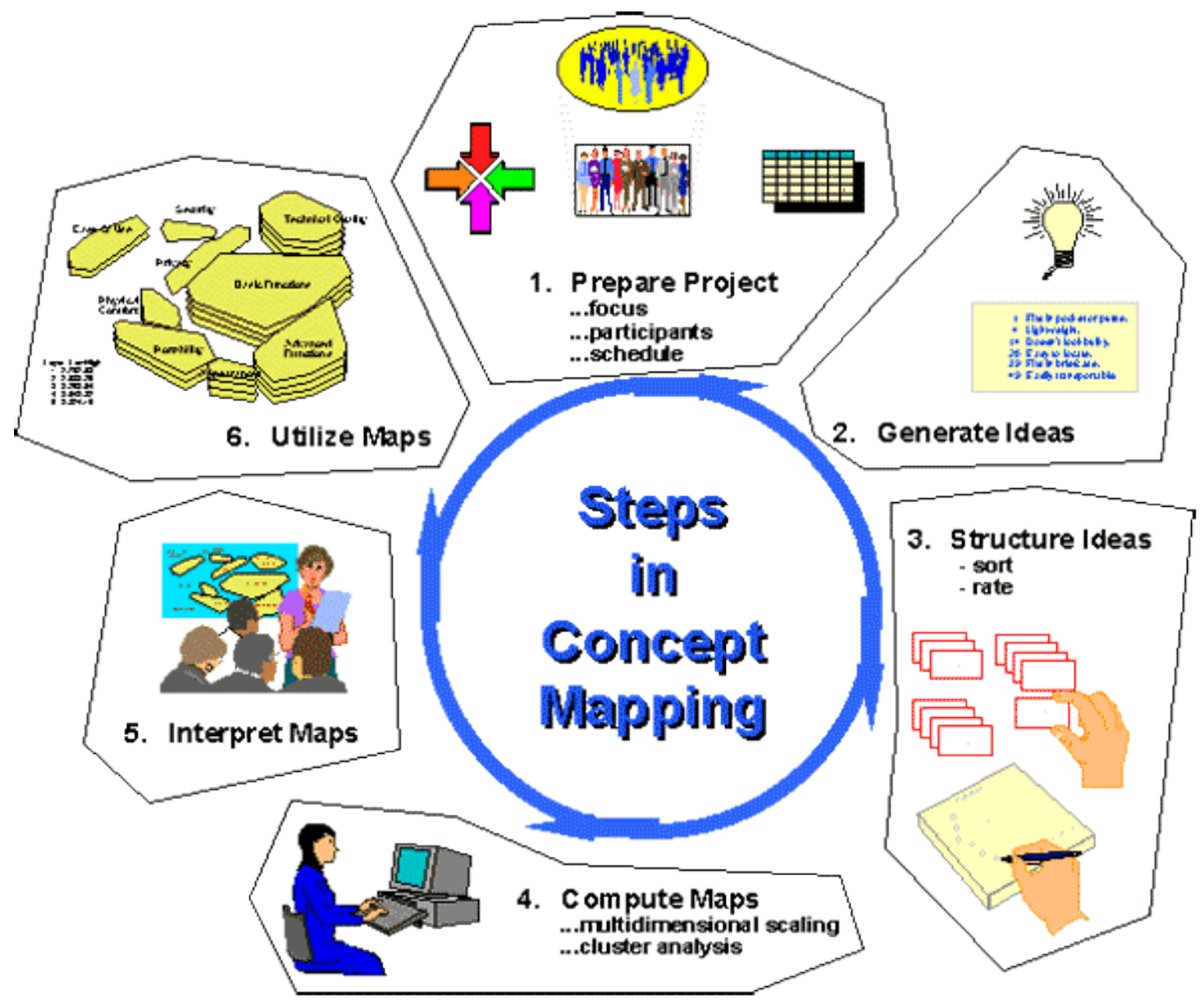


- The researcher introduces a simple characteristic concept map through asking one student to talk about herself. The researcher writes the key concepts on the board e.x ( name, age, favorite subject, and school days). (Sara, 12 years old, English, from Saturday to Thursday)

- The researcher explains to students how to use these words (concepts) to construct a map like the following one. The researcher tells the students that a concept map can take any shape and what matters is introducing the information in the map from the text correctly.

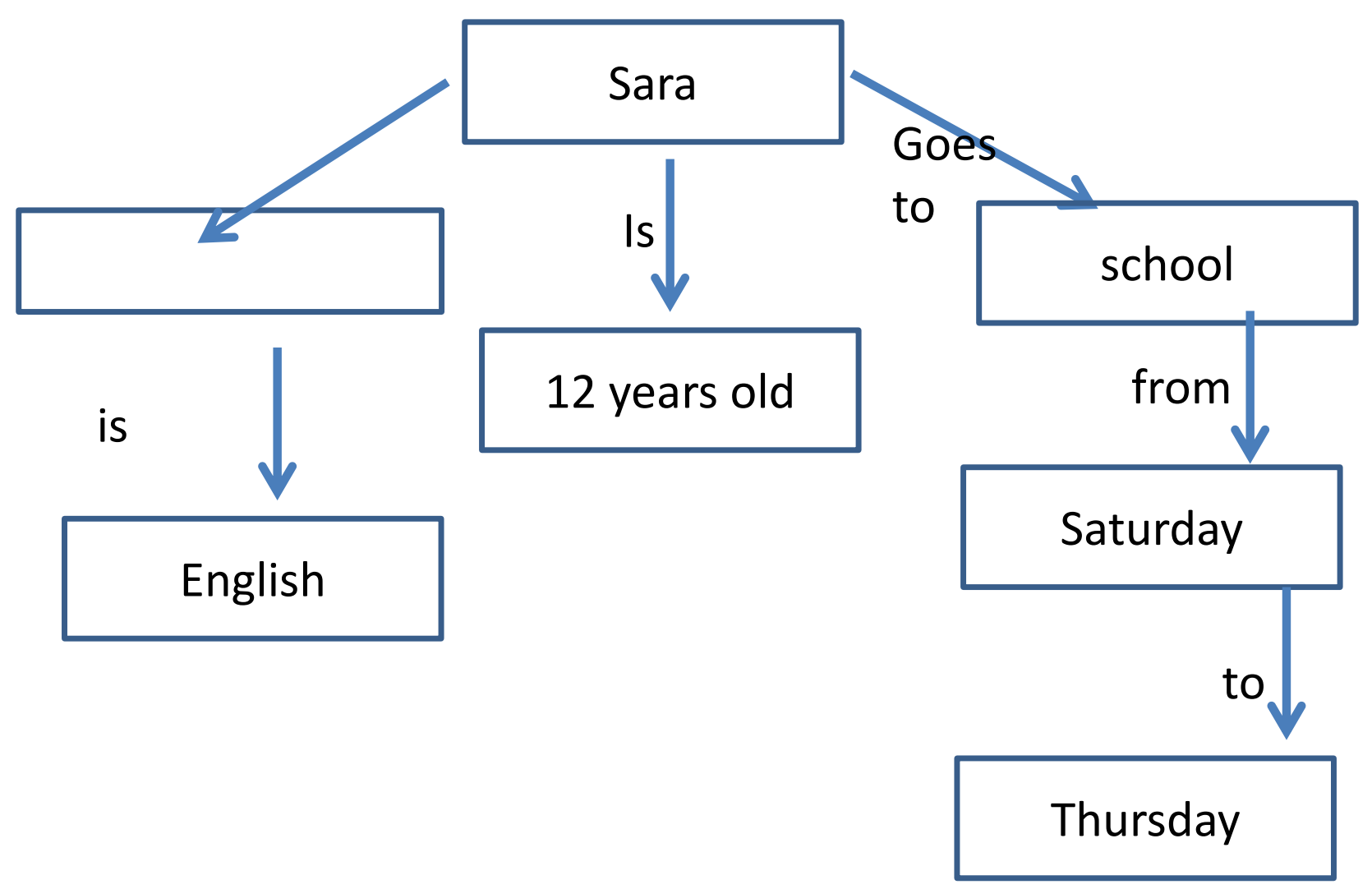

Lesson assessment: 
At the conclusion of this lesson, students are asked to create a concept map about themselves similar to the one of Sara and share them with one another. The objective is for students to reflect on what they have learned, identify gaps in their understanding, and sequentially review the material.

\section{References}

-Afamasaga-Fuata'i, K. (2008). Students' conceptual understanding and critical thinking: A case for concept maps and veer-diagrams in mathematics problem solving. Australian Mathematics Teacher, The, 64(2), 8.

-Atkin, J. M., \& Coffey, J. (Eds.). (2003). Everyday assessment in the science classroom. NSTA Press.

-Chang, K. E., Sung, Y. T., \& Chen, I. D. (2002). The effect of concept mapping to enhance text comprehension and summarization. The Journal of Experimental Education, 71(1), 5-23.

-Chang, K. E., Sung, Y. T., \& Chen, S. F. (2001). Learning through computerbased concept mapping with scaffolding aid. Journal of computer assisted learning, 17(1), 21-33.

-Chularut, P., \& DeBacker, T. K. (2004). The influence of concept mapping on achievement, self-regulation, and self-efficacy in students of English as a second language. Contemporary Educational Psychology, 29(3), 248-263.

-Coutinho, E. (2014). Concept maps: evaluation models for educators. Journal of Business and Management Sciences, 2(5), 111-117.

-Creghan, K. A., \& Creghan, C. (2013). Assessing for achievement. Science and Children, 51(3), 29.

-Duke, N. K., \& Pearson, P. D. (2009). Effective practices for developing reading comprehension. Journal of education, 189(1-2), 107-122.

-Hwang, G. J., Lai, C. L., \& Wang, S. Y. (2015). Seamless flipped learning: a mobile technology-enhanced flipped classroom with effective learning strategies. Journal of Computers in Education, 2(4), 449-473.

-Katayama, A. D., \& Robinson, D. H. (2000). Getting students "partially" involved in note-taking using graphic organizers. The Journal of Experimental Education, 68(2), 119-133.

-Katsumoto, Shuzo, (2003), what is concept mapping, P 1.

-Lynch, M. M. (2002). The online educator: A guide to creating the virtual classroom. Routledge. 
-Novak, J. D., \& Cañas, A. J. (2008). The theory underlying concept maps and how to construct and use them.

-Novak, J. D. (2010). Learning, creating, and using knowledge: Concept maps as facilitative tools in schools and corporations. Routledge.

-Novak,J. D. (1990). Concept Mapping: A Useful Tool for Science Education. Journal of Research in Science Teaching, 27, 939-949.

-Novak, J. D. (1990). Concept maps and Veer diagrams: Two metacognitive tools to facilitate meaningful learning. Instructional science, 19(1), 29-5.

-Novak, J. D. (1998). Learning, Creating and Using Knowledge: Concept Maps as Facilitative Tools in Schools and Corporations Lawrence Erlbaum Associates. Mahwah, NJ.

-Novak, J. D., \& Gowin, D. B. (1984). Learning how to learn. Cambridge University Press.

-Plotnick, E. (1997). Concept Mapping: A Graphical System for Understanding the Relationship between Concepts. ERIC Digest.

-Sánchez, J., Cañas, A. J., \& Novak, J. D. (2010). Concept map: a strategy for enhancing reading comprehension in English as L2. CMC 2010, 29.

-Sullivan, C. S. (1993). Concept mapping: an information processing strategy for reading fifth grade social studies text(Doctoral dissertation).

-Vanides, J., Yin, Y., Tomita, M., \& Ruiz-Primo, M. A. (2005). Concept maps. Science Scope, 28(8), 27-31.

-Willits, V. R. (2002). The effect of concept maps and learning styles on seventh graders' learning of geography. 